\title{
Adenoid Cystic Carcinoma of Larynx
}

Rakesh Srivastava, Junior Resident, Deptt. of Otolaryngology, Naresh Bhatia, Associate Professor, Deptt. of Otolaryngology,

King George's Medical College, Lucknow

Adenoid cystic carcinoma (cylindroma) is most commonly encountered in the major salivary glands but its rare occurrence was also reported from minor salivary gland of oral cavity and upper respiratory tract. While most modern texts credit Theodore Billroth with the first description of this tumour, it has been pointed out by Tauxe et al. in 1962 that a very accurate description of the histopathology and behaviour was reported in the French literature by Robin and his coauthor in 1853 and 1854, using the term 'tumeurs heteradeniques'. A case most probably arising in the trachea was also described by this group. Billroth did coin the term 'cylindroma' in his treatise published in 1856.

\section{CASE REPORT}

A 30 year old male teacher by profession was admitted with history of progressively increasing hoarseness of voice for last 2-1/2 years and difficulty in respiration for last 7 days. Indirect laryngoscopy revealed a large smooth yellowish

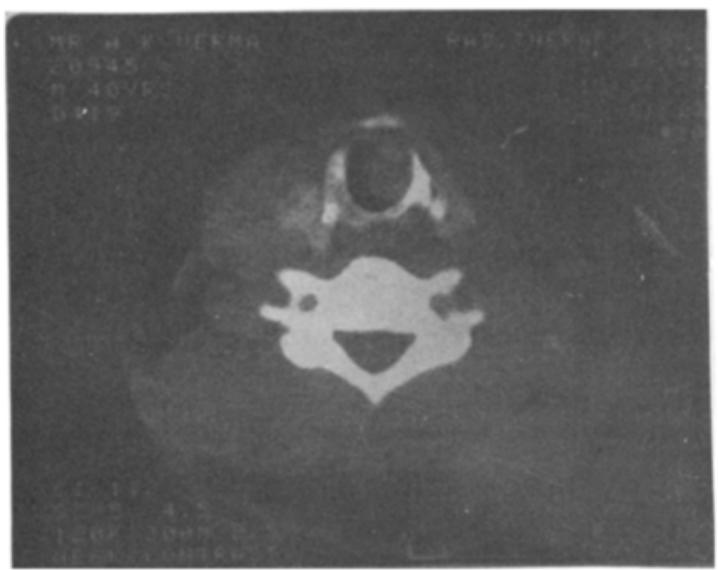

(Fig.1) mass arising from undersurface of left vocal cord. Right cord and both arytenoids were free and chink was inadequate for comfortable breathing. On palpation of neck no mass or lymph node enlargement was noted and laryngeal crepitus was present. CT scan (axial $2 \mathrm{~mm}$ cuts), revealed mass arising from undersurface of left vocal cord and seen in 3 sections (Fig. 1). Flexible fibreoptic laryngoscopy showed a yellowish mass arising from under surface of left vocal cord (Fig. 2). A biopsy performed during the procedure revealed adenoid cystic carcinoma on histopathological examination.

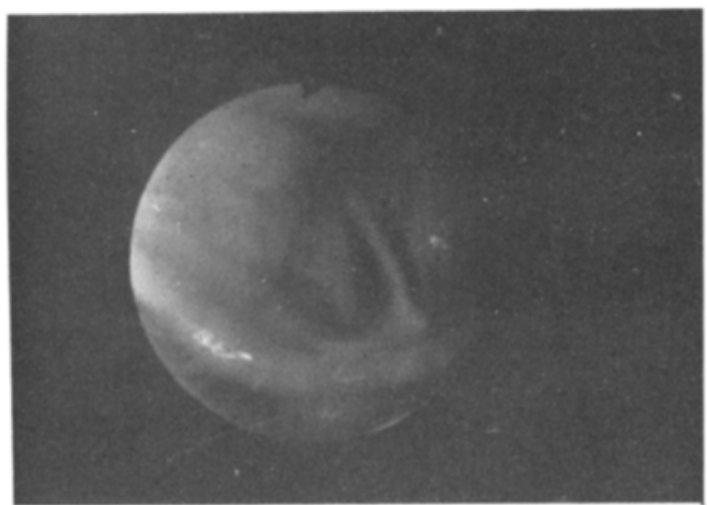

(Fig.2)

Patient was planned for elective tracheostomy and microlaryngoscopic excision under general anaesthesia. Mucosal incision was given by endoscopic knife over the tumour mass which was protruding just underneath the left cord. The dissection was done anteriorly and posteriorly and tumour was delivered 'enbloc'. There was no postoperative complication. Bleeding was minimal during the procedure. In the recovery phase of the anaesthesia, mobility was full in both the cords and adequate respiratory airway was 
restored. Subsequently the patient was decannulated without any difficulty after seventh postoperative day.

The tumour on gross examination was yellowish pink in colour, firm and measuring $6 \mathrm{~mm}$ in size. Histology - sections showed tumour involving connective tissue and composed of atypically proliferated small round epithelial cells which surround small cyst like spaces containing mucinous material or clear spaces. At places the cells are multilayered. They characteristically present a uniform morphology. The stroma consist of hyalinised fibro collagenous tissue Adenoid cystic carcinoma salivary gland type (Fig. 3).

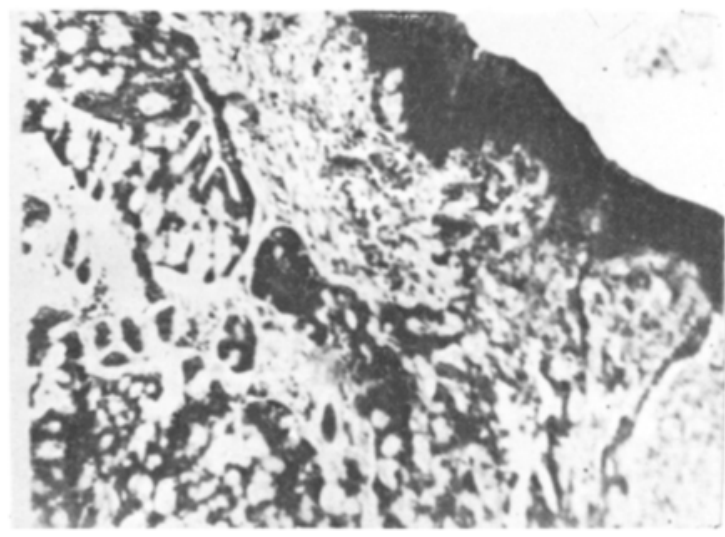

(Fig.3)

\section{FOLLOW UP}

Patient has been followed up monthly for six months. On indirect laryngoscopy there was no recurrence of growth but there is slight thickening of left true cord. Patients's voice was markedly improved. On neck palpation no cervical lymphadenopathy and laryngeal crepitus was present.

\section{DISCUSSION}

Review of existing literature on adenoid cystic carcinoma of larynx as reported by various authors revealed that the age range was wide (2975 years) with peak age in fifth decade. The duration of symptoms being quite variable from three weeks to three years. Batsakis et al. (1980) noted that two thirds of these tumours are subglottic and there is female predominance. The clinical behaviour in larynx mimics adenoid cystic carcinoma elsewhere with early perineural invasion and long term persistence (Tewfik et al. 1983; Sessions et al. 1975). Cervical metastasis is rare, occurring in $10-15 \%$ of cases (Tewfik et al. 1982).

In the present case report the tumour was subglottic and the duration of symptoms was quite long (two and half years). There was no cervical metastasis and the stridor was minimal and a late symptom. The tracheostomy was done to assist in surgery and intubation of patient for general anaesthesia. The early decannulation was done as the tumour is slow growing in nature and it is the question of livelihood of the patient who is a teacher by profession. It was also difficult for the patient to do the tracheostomy care at his residence in a remote area with minimal facilities.

Although there is no general agreement as to the best method of therapy for these type of tumours, most authors advocate wide local excision either with or without radical neck dissection (Spiro, $\mathrm{RH}$ et al., 1973; Whicker. J. H. et al. 1974).

\section{References}

1. Oloffson J and Van Nostrand, A.W.P. (1977): Adenoid cystic carcinoma of the larynx. A report of four cases and review of literature, Cancer 40, 1307-1313.

2. Spiro RH, Koss LG, Hajdu ST and Strong EW. (1973): Tumours of minor salivary origin. A clinicopathologic study of 492 cases, Cancer 31:117-129.

3. Tauxe WH et al. (1962): A century of cylindromas. Short review and report of 27 adenoid cystic carcinomas arising in the upper respiratory passage, Archives of Otolaryngology, 75: 364-376.

4. Tewfik CL, Novick WH et al. (1983): Adenoid cystic carcinoma of the larynx, J Otolaryngol 12:151.

5. Whicker $\mathrm{H}, \mathrm{Neel} H \mathrm{HB}$, Weiland $L \mathrm{H}$ and Devine $K D$, (1974): Adenocarcinoma of the larynx. Annals of Otolaryngology 83: $487-490$. 